\title{
Differences between LCA for analysis and LCA for policy: a case study on the consequences of allocation choices in bio-energy policies
}

\author{
Tjerk Wardenaar • Theo van Ruijven • \\ Angelica Mendoza Beltran • Kathrine Vad • \\ Jeroen Guinée • Reinout Heijungs
}

Received: 5 July 2011 / Accepted: 9 April 2012 /Published online: 8 May 2012

(C) The Author(s) 2012. This article is published with open access at Springerlink.com

\begin{abstract}
Purpose The increasing concern for adverse effects of climate change has spurred the search for alternatives for conventional energy sources. Life cycle assessment (LCA) has increasingly been used to assess the potential of these alternatives to reduce greenhouse gas emissions. The popularity of LCA in the policy context puts its methodological issues into another perspective. This paper discusses how bio-electricity directives deal with the issue of allocation and shows its repercussions in the policy field.

Methods Multifunctionality has been a well-known problem since the early development of LCA and several methods have been suggested to deal with multifunctional processes. This paper starts with a discussion of the most common allocation methods. This discussion is followed by a description of bio-energy policy directives. The description shows the increasing importance of LCA in the policy
\end{abstract}

Responsible editor: David Pennington

T. Wardenaar

Science System Assessment, Rathenau Instituut,

P.O. Box 95366, The Hague, The Netherlands

T. van Ruijven

Faculty of Technology, Policy and Management,

Delft University of Technology,

P.O. Box 5015, Delft, The Netherlands

A. M. Beltran

Netherlands Environmental Assessment Agency,

P.O. Box 303, Bilthoven, The Netherlands

K. Vad $\cdot$ J. Guinée $\cdot$ R. Heijungs $(\bowtie)$

Institute of Environmental Sciences, Leiden University,

P.O. Box 9518, Leiden, The Netherlands

e-mail: heijungs@cml.leidenuniv.nl context as well as the lack of consensus in the application of allocation methods. Methodological differences between bio-energy directives possibly lead to different assessments of bio-energy chains. To assess the differences due to methodological choices in bio-energy directives, this paper applies three different allocation methods to the same bioelectricity generation system. The differences in outcomes indicate the importance of solving the allocation issue for policy decision making.

Results and discussion The case study focuses on bioelectricity from rapeseed oil. To assess the influence of the choice of allocation in a policy directive, three allocation methods are applied: economic partitioning (on the basis of proceeds), physical partitioning (on the basis of energy content), and substitution (under two scenarios). The outcomes show that the climate change score is assessed quite differently; ranging from $0.293 \mathrm{~kg}$ to $0.604 \mathrm{~kg} \mathrm{CO}_{2} \mathrm{eq} / \mathrm{kWh}$. It is argued that this uncertainty hampers the optimal use of LCA in the policy context. The aim of policy LCAs is different from the aim of LCAs for analysis. Therefore, it is argued that LCAs in the policy context will benefit from a new guideline based on robustness.

Conclusions The case study confirms that the choice of allocation method in policy directives has large influence on the outcomes of an LCA. With the growing popularity of LCA in policy directives, this paper recommends a new guideline for policy LCAs. The high priority of robustness in the policy context makes it an ideal starting point of this guideline. An accompanying dialog between practitioners and commissioners should further strengthen the use of LCA in policy directives.

Keywords Allocation - Bio-electricity · LCA · Policy · Rapeseed $\cdot$ Renewable energy 


\section{Introduction}

The increasing concern for possible adverse effects of climate change, has spurred the search for alternatives for conventional energy production systems. Biomass based energy (fuel, heat and electricity), or bio-energy, has in this respect been promoted as a promising alternative. Bio-energy is believed to be more sustainable than the conventional energies obtained from fossil fuels (Chum et al. 2011).

Moreover, it is believed that bio-energy increases countries' energy security and to create opportunities for rural development. As a consequence bio-energy is stimulated via environmental and energy policies in both developed and developing countries (Worldwatch Institute 2007; United States Department of Energy 2010; Van der Voet et al. 2010).

Despite these advantages, bio-energy is increasingly linked to adverse effects on the environment and on society. Questions have been raised with respect to impacts on food, land and water availability (Bindraban and Pistorius 2008; De Fraiture et al. 2008). Another criticism concerns the alleged impacts on land use changes and the destruction of tropical rain forest (Searchinger et al. 2008). Also the presumed reductions in greenhouse gas (GHG) emissions are questioned (Reijnders and Huijbregts 2008). In a response to these more critical stances to bio-energy, governments have introduced directives with the intention to stimulate sustainable bio-energy (SenterNovem 2008; UNEP 2009). Life cycle assessment (LCA) plays an important role in these directives and it often serves as the main tool to assess alternative energy production systems' reductions in GHG emissions. In this way, policymakers are faced with methodological decisions central to LCA, e.g. with respect to the allocation method. This article reviews various bio-energy directives and discusses how their differences with respect to the recommended allocation methods may influence the assessment of bio-energy systems. It does so in order to stimulate the discussion on distinguishing LCAs for the purpose of analysis (finding hotspots, monitoring, process optimization, etc.) and LCAs for policy purposes (banning, subsidizing, certifying, etc.).

This paper is organized as follows. Section 2 sketches the issues of allocation and how it has been dealt with in policy guidelines on bio-energy. Section 3 describes a case study on electricity with rape seed, using several allocation principles. Sections 4 and 5 discuss and conclude.

\section{Allocation: practice, policy and problems}

\subsection{Allocation methods}

During the inventory phase of an LCA the problem of multifunctional processes, and thus of allocation, is often encountered. Following Guinée (2002), a multifunctional process is considered as "a unit process yielding more than one functional flow, i.e. co-production [more than one product outflow], combined waste processing [more than one waste inflow] and recycling [one or more product outflows and one or more waste inflows]".

Multifunctional processes are a problem for LCA because usually not all the functional flows are part of the same product system. Thus, a multifunctional process is part of the product system studied and also of other systems. The question is then, how to allocate the environmental impacts of this multifunctional process to the different product systems, i.e. to the different functional flows.

The LCA community has come up with various ways to address the multi-functionality problem. The on-going debate on allocation triggers the question whether there actually is a 'correct' way to address this problem. It can be argued that by focusing on the physical relationships behind the process this question can be answered positively. However, this argument has so far not been able to bring the allocation debate to an end (see also Weidema and Schmidt 2010 for a summary of recent discussions on allocation). Three types of reasons for this can be identified; (1) there are always various physical relationships to choose from for a multifunctional process, (2) different co-product can be expressed in different physical quantities (e.g. mass and energy), and (3) physical relationships do not necessarily reflect properly the ground for existence of a process (like mass for processes co-producing medicines in small amounts and fodder in big amounts).

In this article, the on-going debate on allocation is seen as a sign that the question above should be answered negatively. It follows in this respect the assertion of Guinée et al. (2004) that "the multi-functionality problem is an artefact of wishing to isolate one function out of many. As artefacts can only be cured in an artificial way, there is no 'correct' way of solving the multi-functionality problem, even not in theory." The most frequently used methods to solve this problem are shortly introduced below. The introduction discusses not only the rationales behind the methods, but also discusses their advantages and flaws:

Subdivision: disentangling a process that has been recorded as a multi-functional unit process into the constituent mono-functional unit processes

System expansion: avoiding the multi-functionality problem by broadening the system boundaries and introducing new processes and several functional units Physical partitioning: the artificial splitting up of a multifunctional process into a number of independently operating mono-functional processes, based on physical properties of the flows (e.g. mass, energy, carbon content, etc.) 
Economic partitioning: the artificial splitting is based on economic properties of the multifunctional process, such as the gross sales value or the expected economic gain

In order to come to a standardization of LCA, International Organization for Standardization (ISO) introduced a hierarchical approach for dealing with multi-functionality. The ISO 14044 allocation procedure (clause 4.3.4.2) prescribes subdivision or system expansion as a first step in order to avoid actual allocation. In case allocation cannot be avoided ISO prescribes physical partitioning as a second step. The procedure emphasizes that this type of partitioning should reflect the underlying physical relationship between the different products or functions. As a third step, when physical partitioning cannot be established, ISO prescribes allocation in a way that reflects another (e.g. economic) relationship between the different products or functions (ISO 14040 2006).

In addition to these allocation methods mentioned in the ISO standard, there is the often used approach of substitution:

Substitution: the concept behind substitution is that the production of a co-product by the system studied causes another production process in another system to be avoided. This avoided production process results in avoided emissions, resource extractions etc. that should be subtracted from the studied product system

Several authors have argued that substitution is conceptually equivalent to system expansion (e.g. Ekvall and Tillman 1997; Finnveden and Lindfors 1998). Conceptually equivalent does not mean that system expansion and substitution provide the same results, but that they provide results that are compatible. ${ }^{1}$ The two allocation methods share subsequently some advantages and disadvantages. Both methods, for example, increase the level of complexity by adding extra processes, either to be added, or to be subtracted. A consequence of the conceptual equivalency between the two approaches is that it is used as an implicit argument to choose for substitution, while still claiming compliance to ISO.

It is important to note, however, that there are also large differences between these methods. An important drawback that is particular for system expansion concerns the fact that the system provides more than one function, so that a multiple functional unit is used. It can be questioned whether an LCA that aims at studying the environmental burdens

\footnotetext{
${ }^{1}$ In order to compare system I that produces products $\mathrm{A}$ and $\mathrm{B}$ simultaneously with system II that produces product $B$, it is the same to add to system II the production system of product B (system expansion) or to subtract from system I the same production system (substitution).
}

of one specific function, achieves this aim when it gets an answer for several functional units. Drawbacks specific for substitution are related to the various assumptions that have to be made. For example, it has to be argued which production process is actually avoided.

Physical partitioning is one of the simplest allocation methods to apply, and if one carefully chooses the physical characteristic used as basis for the method, it is quite straightforward to apply. However, determining the physical characteristics to be used as a basis for allocation can be challenging. Potentially relevant characteristics should relate to the purpose or use of the product. But co-products often have different purposes (or uses) and thus different characteristics may be relevant in understanding why they are sold. In many cases, the LCA practitioner can overcome this problem by selecting a physical characteristic that make sense for both product and co-product. However, such a common denominator cannot always be identified, e.g. a system that produces both meat and leather, or a waste incinerator that fulfills the function of waste processing and the function of energy production.

Economic partitioning is another often applied allocation method. By taking the economic value of different processes as a basis for allocation, economic partitioning addresses the economic motivation behind a multifunctional process. While some practitioners see this as strength, it can also be seen as the main drawback to economic partitioning. Another argument against economic partitioning is that prices can fluctuate independently from the long term economic value of a process. Also, the fact that prices can vary between different locations is sometimes seen as a disadvantage of economic partitioning (Ayer et al. 2007).

\subsection{Allocation in policy guidelines}

Early political visions included high level of biofuel incorporations into transport fuels with no restrictions of origin or production pathways (CEC 2007). However, in a response to the more critical stances to bio-energy, governments have introduced directives with the intention to stimulate sustainable bio-energy only (RTFO 2007; Directive 2009/28/EC, 2009; LCFS 2007; EPA 2010). LCA plays an important role in these regulations as it often serves as the main tool to assess alternative energy production systems' reductions in GHG emissions.

The European Union and the USA have led the way in using LCA in regulatory schemes. The first schemes appeared in individual European Member States. The UK implemented the Renewable Transport Fuel Obligation (RTFO) in 2007, which requires transport fuel providers to report the sustainability level of the fuels provided in the UK (RTFO 2007). For the GHG criterion, the scheme required that reporting parties calculate the carbon intensity of their 
fuel based on a specified LCA methodology, including using a 'restricted' substitution method for allocation. The RTFO restricted the substitution method by only allowing some uses for specific co-products (e.g. rapeseed cake could only be used for animal fodder). However, for certain chains, it was not possible to identify the use of the coproduct. In these cases, economic partitioning was used, as it was felt to be the closest allocation method to substitution (RTFO 2007; Table 1).

Having set ambitious targets for the use of biofuels in Europe $(10 \%$ renewable in the transport sector by 2020 ; CEC 2007), the European Commission published, in 2009, a directive with the goal to ensure the sustainability of biofuels and bioliquids (Directive 2009/28/EC, 2009). The Renewable Energy Directive (RED) defines a minimum threshold for GHG emission savings that must be achieved by bio-fuels to be considered renewable energy. The calculation methodology for GHG savings is also defined in the directive. The directive imposes to use energy content as basis for allocation, except for electricity that is co-produced with biofuel or bioliquid, and which, under certain conditions, should be allocated applying substitution (Directive 2009/28/EC 2009). As a European directive, the RED will be transposed into national legislation in European member states. In case of UK, this means that the guidelines of the RED are being implemented in the RTFO.

The US has also recently seen the development of two schemes regulating the GHG emissions of their transport fuel. The first, the Low Carbon Fuel Standard (LCFS 2007), was set in place in California. This scheme defines an average maximum carbon intensity target for the mix of transportation fuels used in California. Transport fuels that have lower carbon emissions than the target are awarded credits, which they can sell to compensate fuels that are too carbon intensive. The credits and debits are awarded based on the life cycle GHG emissions of transportation fuels. The LCFS requires substitution to be used as allocation method (LCFS 2007). However, in practice some chains use physical partitioning on the basis of energy content (CEPA 2009).

A federal regulation is also under preparation in the USA, the Renewable Fuels Standard 2010 (EPA 2010), which requires the US Environmental Protection Agency (EPA) to calculate the carbon intensity of the biofuels becoming available most likely in the USA. EPA's results will then be used to classify the fuels into four different categories (cellulosic biofuel, biomass-based diesel, advanced biofuel and renewable fuel), which each have different volume targets. EPA performed their LCA calculations applying a substitution method in case of multi-functional processes.

\subsection{Discussion}

The schemes presented in this section are not only distinguishable by their geographical scope. Their reporting requirements have led them to implement different allocation methods. Most European schemes require industries to calculate and report their GHG emissions themselves, so the allocation methods applied have to be simple. And indeed, even the RTFO only employs a 'restricted' substitution. In the American schemes, calculations are performed with support of given default values that industries have to use. These default values can only be changed under specific conditions, and only by the scheme's implementation body. Therefore, the American schemes can use somewhat more complex allocation methods.

This diversity in reporting requirements is confusing for bio-energy producers and users. As most modern markets, the bio-energy market has a global character and consists of international actors and relationships. Moreover, the use of different allocation methods in different schemes is not only confusing but also disturbing. After all, different allocation methods potentially lead to different assessments of a single bio-energy stream (Kim and Dale 2002; Wang et al. 2004; Guinée and Heijungs 2007; Thomassen et al. 2008; Bier et al. 2012). To assess whether it can be expected that the different requirements in the schemes above result in different assessments, they are applied on a case study below. To serve its purpose of illustration, a real life case study has been selected that is relatively simple and straightforward, focusing on GHGs only and leaving out of the analysis other impacts (including direct and indirect land use change that may obviously be an important issue) and further methodological discussions. In this way, the case serves as a suitable test on whether the problem is real or only hypothetical.
Table 1 Overview of bio-energy directives

\begin{tabular}{lll}
\hline Legislation & Region covered & Allocation method \\
\hline $\begin{array}{l}\text { Renewable Transport } \\
\begin{array}{l}\text { Fuel Obligation } \\
\text { Renewable Energy Directive }\end{array}\end{array}$ & $\begin{array}{c}\text { European Union } \\
\text { (all 27 Member States) }\end{array}$ & $\begin{array}{l}\text { Substitution whenever possible, if not } \\
\text { allocation based on economic value } \\
\text { Allocation based on energy content except } \\
\text { for electricity co-production for which it is } \\
\text { substitution }\end{array}$ \\
Low Carbon Fuel Standard & California & $\begin{array}{l}\text { Substitution whenever possible, if not } \\
\text { allocation based on energy content } \\
\text { Renewable Fuel Standard 2010 }\end{array}$ \\
\hline
\end{tabular}




\section{Case study on rapeseed}

\subsection{Goal and scope}

The discussion above shows that different countries promote different guidelines with respect to addressing multifunctional processes. The goal of this LCA study is to assess the influences of the choice of allocation on the outcomes of an LCA.

Previous studies have already used a similar approach using a hypothetical case (Guinée et al. 2009; Luo et al. 2009). In the present study, the allocation methods are applied on an existing bio-electricity chain. The chain selected is the rapeseed to bio-electricity chain.

The electricity production for the Dutch mix was used as a reference chain and renewable energy resources were not considered to contribute in this mix. This comparison took place only for one impact category: climate change.

The selected functional unit for the case study was: The production of $1 \mathrm{kWh}$ low voltage electricity at the Dutch grid. For the case study, main data sources were Hamelinck et al. (2008) and Van der Voet et al. (2008). To check data from these sources and when additional data was needed, the ecoinvent database was consulted, especially for agriculture (Nemecek et al. 2000). The CMLCA 5.0 software, accessed via www.cmlca.eu, was used as a calculation platform.

\subsection{Life cycle inventory analysis}

The chain consists of five main life cycle stages: the feedstock production, the feedstock transport, the conversion, the oil transport and the electricity generation. For the system boundaries definition, two main assumptions were made:

1. A distinction between 'negative' and 'positive' $\mathrm{CO}_{2}$ emissions. All $\mathrm{CO}_{2}$ emissions from the feedstock production phase (rapeseed cultivation) were considered (positive) emissions to the environment, while $\mathrm{CO}_{2}$ fixation in the same phase was considered a negative emission (or extraction from the environment). For all other emission, this distinction was not made and the carbon emissions are still accounted for (including that released upon combustion).

2. Emissions from electricity production are included as well as emissions from the production of input materials and energy to all other processes (e.g. fertilizers production, electricity used for conversion processes, among the main ones).

The flow diagram in Fig. 1 provides an outline of all the major unit processes in the system. The flow diagram is based on the flow diagrams of Hamelinck et al. (2008) and

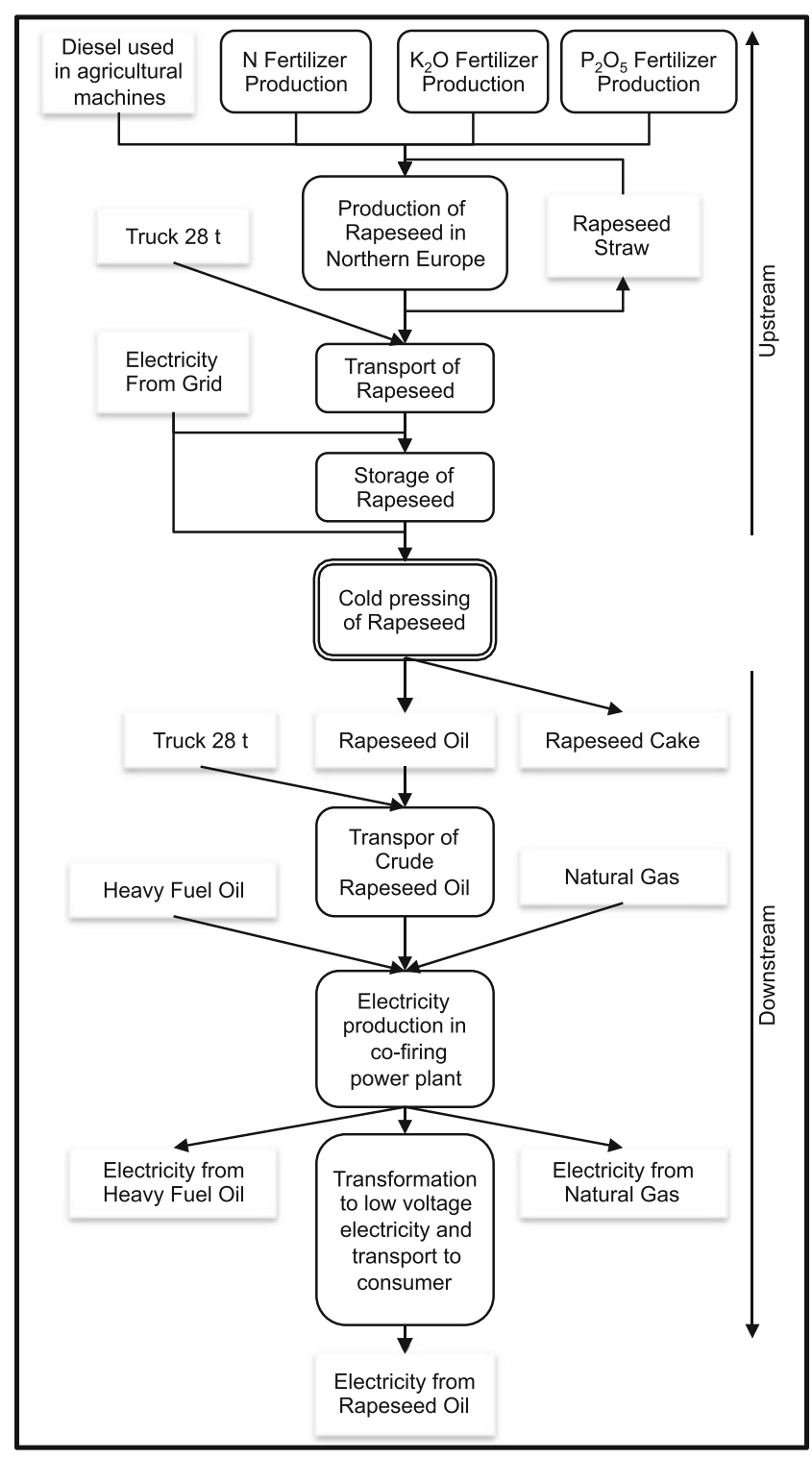

Fig. 1 Flow diagram rapeseed to electricity chain

of van der Voet et al. (2008). It is remodeled and specified for the present case study.

It was assumed that rapeseed is cultivated and produced in Northern Europe as well as it was assumed that the rapeseed straw generated during the harvesting process is plowed back to the ground replacing part of the nitrogen fertilizer. The rapeseed is then transported to the conversion plant where the oil will be extracted. The estimated requirement for this transportation is $150 \mathrm{tkm}$ within the Netherlands or between Germany and the Netherlands.

Once the rapeseed is at the conversion plant, two main processes take place in order to extract the oil: (1) storage and (2) cold pressing of the rapeseed. Out of the pressing process, two products are obtained: the rapeseed oil and the rapeseed cake. This was the process for which the multifunctionality problem was solved by applying the different 
allocation methods. Hence, special focus is given to this process. Afterwards, the oil is transported from the conversion plant to the power plant where it is combusted in order to produce electricity. It was estimated again that transportation requirements was $150 \mathrm{tkm}$. Co-firing with heavy oil and natural gas was the chosen technology in the chain for the bioelectricity generation process. This process involves also another multi-functionality problem due to the three economic inflows it has (heavy oil, natural gas and rapeseed oil). In order to concentrate on the multi-functionality problem from the conversion process (pressing process), the energy production was allocated on the basis of the energy content: $37 \%$ to the rapeseed oil, $37 \%$ to the natural gas and $46 \%$ to the heavy oil. Two more processes take place in order to deliver the electricity to the consumer: the conversion of the electricity produced from high voltage to low voltage and the transportation of the electricity to the consumer.

Since the core point of the case study is to analyze the difference in the results when using different allocation methods, the allocation methods used in the bio-energy directives were applied to the multifunctional process in the conversion phase (pressing process). The allocation methods applied were thus: substitution, physical partitioning (on the basis of energy content) and economic partitioning (on the basis of proceeds).

As mentioned above, a difficulty for the substitution method is to determine which product is replaced by the co-product of the studied system. The case study includes two alternative cases of substitution: (1) substitution of soybean meal and (2) substitution of peas.

In the case of substitution of soybean meal, a loop is created: soybean meal is obtained together with soybean oil and soybean oil substitutes rapeseed oil. To deal with such a loop, practitioners can rely on two different approaches. First, ignore the fact that soybean meal and oil are coproduced and close the loop by including soybean meal alone. Second, extent the system by including the co-produced soybean oil and apply a form of partitioning. The use of the first approach implies a less realistic assumption, as these products are indeed co-produced. The use of the second approach is simpler and more realistic and still serves the illustrative purpose of the case study. Therefore, the second approach was chosen and economic partitioning was applied to the extraction process when substituting with soybean meal. It should be noted however that this is a simplification of the substitution method.

Therefore an alternative - and less realistic — case of substitution of peas has been added. This application is straightforward as peas production is not associated with any coproducts requiring allocation. The substitution in terms of protein can be considered as a simplification but it serves the illustrative purpose of the case study and is in line with energy policies.
Table 2 Substitution ratios

\begin{tabular}{lll}
\hline Substituted product & $\begin{array}{l}\text { Protein content } \\
(\text { mass \%) }\end{array}$ & $\begin{array}{l}\text { Substitution ratio } \\
\text { (rape/substrate) }\end{array}$ \\
\hline Soybean meal & 45 & 0.75 \\
Peas & 24 & 1.5 \\
\hline
\end{tabular}

The resulting substitution ratios are shown in Table 2 . They are calculated based on the protein content of rapeseed cake, soybean meal and peas (Brookes 2001; Corbett 2008). Table 3 shows the allocation ratios used for the partitioning methods. With the allocation ratios, it is possible to allocate the burdens (emissions to air) between the rapeseed oil and rapeseed cake from the pressing process.

The emissions generated in processes taking place before the pressing process (i.e. upstream of the multifunctional process), are the ones allocated to the two products that result from pressing rapeseed (i.e. rapeseed oil and rapeseed cake) with the different allocation ratios from different allocation methods. The downstream emissions (those being emitted in processes after the pressing process) correspond to the total emissions of the chain calculated with a surplus method and subtracting the upstream emissions. The upstream and downstream emissions are shown respectively in Tables 4 and 5 .

\subsection{Life cycle impact assessment of the case study}

The only impact category analyzed was the climate change category. The inventory results of GHG emissions to air in $\mathrm{kg}$ were transformed to kilogram of $\mathrm{CO}_{2}$ equivalents. The Global Warming Potential for a 100-year time horizon developed by the Intergovernmental Panel on Climate Change was used as the characterization factor (IPCC 2007).

The climate change profile obtained for the rapeseed oil to bioelectricity chain by using different allocation methods is shown in Table 5. The results are compared to a reference chain and the improvement is also calculated. The reference chain is the Dutch production mix based on fossil fuels and nuclear energy (Van der Voet et al. 2008). The composition of the Dutch electricity mix is given in Table 6 (Seebregts and Volkers 2005; CBS 2007):

The total GHG emissions of the reference chain are $0.715 \mathrm{Kg}$ of $\mathrm{CO}_{2}$ equivalents. The percentage of improvement is calculated by subtracting the total GHG emissions of the bio-electricity chain from those of the reference chain

Table 3 Allocation ratios used in case study

\begin{tabular}{lcc}
\hline Method & Rapeseed oil & Rapeseed cake \\
\hline Economic partitioning & 0.70 & 0.30 \\
Physical partitioning & 0.55 & 0.45 \\
\hline
\end{tabular}


Table 4 Partial inventory table for upstream part of bio-electricity chain

\begin{tabular}{ll}
\hline elementary flow & Upstream emission to air $\left(\mathrm{kg} \mathrm{CO}_{2}\right.$ eq $)$ \\
\hline Carbon dioxide to air & 0.246 \\
Nitrous oxide $\left(\mathrm{N}_{2} \mathrm{O}\right)$ to air & 0.00199 \\
Methane to air & 0.000324 \\
\hline
\end{tabular}

and then dividing it by the total GHG emissions of the reference chain:

$\mathrm{GHG}_{\text {reduction }}(\%)=\frac{\mathrm{GHG}_{\text {emission,fossil chain }-\mathrm{GHG}_{\text {emission,bio-chain }}}}{\mathrm{GHG}_{\text {emission,fossil chain }}} \times 100$

As Table 7 shows, the allocation method used has a substantial influence on the results of the impact assessment. The method leading to the largest indicator of improvement is the substitution of peas $(\sim 60 \%)$; followed by physical partitioning on energy basis $(\sim 35 \%)$. Finally, the substitution of soybean meal and the economic partitioning lead to approximately $20 \%$ improvement.

\section{Discussion}

The outcomes of the case study show that the choice of allocation method can have a considerable impact on the outcomes of an LCA, even for a system that is small, and where the allocation issue has been restricted to one process. The outcomes in this study range between a 16 and $60 \%$ improvement compared to a reference chain. And although substitution with peas tilts the picture with its extreme outcome, it should be noted that the other methods still produce outcomes that range from 16 to $33 \%$.

Allocation methods are frequently required in LCA, especially when complex systems, like energy production systems, are involved. At this moment, directives regarding the assessment of bio-energy production still prescribe different allocation methods. As the case study shows, this poses a problem because the outcomes of LCA differ strongly, depending on which directive is followed. In the EU, the Renewable Energy Directive is likely to lead to standardization of national arrangements but differences between the EU and the USA will remain. Also, transposition of the RED

Table 5 Partial inventory table for downstream part of bio-electricity chain

\begin{tabular}{ll}
\hline Elementary Flow & Downstream emission to air $\left(\mathrm{kg} \mathrm{CO}_{2}\right.$ eq $)$ \\
\hline Carbon dioxide to air & 0.012 \\
Nitrous oxide $\left(\mathrm{N}_{2} \mathrm{O}\right)$ to air & 0.00 \\
Methane to air & 0.000019 \\
\hline
\end{tabular}

Table 6 Reference chain: Dutch electricity mix

\begin{tabular}{llll}
\hline Source & Mix (\%) & Efficiency (\%) & Remark \\
\hline Natural gas & 52.0 & 43 & \\
Hard coal & 43.6 & 39 & \\
Nuclear & 4.1 & & $90 \%$ pressure water reactor, \\
& & & \\
Industrial gas & 0.1 & 36 & \\
Oil & 0.1 & 44 & \\
\hline
\end{tabular}

in national legislation might still result in diverse application of allocation methods due to differences in interpretation. And even when similar allocation methods are used within a single sector, different outcomes can be obtained due to methodological difficulties or a lack of reliable data.

As noted above, this diversity in policy directives is confusing and disturbing for bio-energy producers and bioenergy users. The resulting differences, due to methodological choices, in the assessments of countries are hard to justify in a policy context. Besides, this uncertainty adds on to other uncertainties for example those related to data issues. With the (economic) stakes high, the uncertainty due to methodological choices might lead to legal problems. Bio-energy producers, for example, may consider a different assessment in another country as an indirect trade barrier.

To avert such a situation, we argue that it is important to discriminate between analysis and policy related LCAs. In the history of LCA, important distinctions between LCA types have already been introduced, most notably attributional versus consequential LCAs, and recent attempts in the ILCD handbook (European Commission-Joint Research Centre-Institute for Environment and Sustainability 2010). Our distinction focuses not on type, but on requirements on LCAs. Analysis-related LCAs are LCA studies that are carried out for the purpose of understanding a certain system. They try to identify important impacts, main contributors to impacts, opportunities to reduce impacts or otherwise optimize the

Table 7 Greenhouse gas emissions of bio-electricity chain

\begin{tabular}{lccc}
\hline Allocation method & $\begin{array}{l}\mathrm{GHG} \text { (in } \\
\mathrm{kg} \mathrm{CO}_{2} \text { eq) }\end{array}$ & $\begin{array}{l}\text { Performance } \\
\text { compared to } \\
\text { reference chain }\end{array}$ & $\begin{array}{l}\text { Improvement } \\
\text { (\%) }\end{array}$ \\
\hline $\begin{array}{l}\text { Economic } \\
\text { partitioning } \\
\text { (on the basis } \\
\text { of proceeds) }\end{array}$ & 0.604 & -0.111 & +16 \\
$\begin{array}{c}\text { Physical partitioning } \\
\text { (on the basis of } \\
\text { energy content) }\end{array}$ & 0.477 & -0.238 & +33 \\
$\begin{array}{c}\text { Substitution } \\
\text { (by soybean) }\end{array}$ & 0.567 & -0.148 & +21 \\
$\begin{array}{l}\text { Substitution } \\
\text { (by peas) }\end{array}$ & 0.293 & -0.422 & +60 \\
\hline
\end{tabular}


system, as well as to analyze the effects of data, assumptions, and choices. Understanding and presenting uncertainties and trade-offs in such an assessment adds to the aim of completeness. Policy-related LCAs, on the other hand, support the regulation of the production, trade and use of certain products. They try to support the governance of industrial systems through subsidizing or certifying desired products, or by taxing or banning undesired products. High levels of uncertainty in this context might lead to inconsistent policy, resulting in strategic behavior of involved actors or in legal disputes. We argue therefore that this difference in aims should be taken into account when setting up an LCA study. As the understanding of the system under study is the main aim of analysisrelated LCA, trade-offs and uncertainties that are encountered during the performance of such LCAs can be handled in line with the views of the involved researcher as long as choices are transparently displayed. The main aim of policy related LCA is to deliver comparable results. As differences in the handling of trade-offs and uncertainties in LCAs can impede the comparability of results, it is of great importance to present clear and straight-forward applicable guidelines for such choices in a policy context.

We argue that there is not an objectively correct way to solve the multi-functionality problem, but the problem can be solved in a way that serves the aim of the LCA best. In a policy context, LCAs should contribute to long-term stability in the system, provide actors equal and full information, and create a level playing field. In other words, policy-related LCAs aim for consistency and robustness. This aim for robustness is not served by the existing guidelines of ISO. As discussed above, ISO strives in the first place for completeness. In practice, this turns out to be difficult due to methodological difficulties and problems with missing or unreliable data. The use of LCA in the policy context should therefore benefit to a great extent from a guideline based on robustness.

It is beyond the scope of this article to draw the outlines of such a guideline, but we foresee that the recommended allocation method within the bio-energy context will be physical partitioning based on energy content. After all, physical partitioning is relatively easy to apply, the data is unambiguous, the outcomes are stable over time and energy-content is the most common denominator of co-products in bio-energy LCAs. Although this choice will not be able to remove all uncertainty (it does not address for example data issues), the method's stability will increase the robustness of policy outcomes.

\section{Conclusions}

The aim of this article was to show to what extent a choice of allocation method can influence the outcomes of an LCA on bio-electricity production. The outcomes of a case study on a rapeseed-to-bio-electricity chain showed that variation between 16 and $60 \%$ reduction of GHG emissions in comparison to a reference chain can be obtained depending on the allocation method applied. These findings emphasize the urgency to develop a clear guideline for LCA practice as using different allocation methods can, intentionally or unintentionally, result in very different outcomes.

Current policies, originating from different regions, prescribe different allocation methods. The recent EU's Renewable Energy Directive introduces some uniformity for EU member states but differences with the US and other world regions will remain. Moreover, national governments can still end up with different regulations due to different interpretations of the EU directive. The undesirability of this situation lays it the uncertainty for bio-energy producers and consumers.

To overcome this situation, we focused on an important difference between scientific and policy LCAs. Whereas the former aims for completeness, the latter aims for robustness. The use of LCA in the policy context will benefit largely from the acceptance of this difference and by drawing up a guideline that is based on the aim of robustness. This paper serves as a starting point for realizing such a guideline. We think that in such a guideline physical partitioning on energy content is the favored allocation method. However, we do not deny the fact that physical partitioning on energy content has its own drawbacks. We urge therefore that the drafting of this guideline should be accompanied by an on-going dialog between practitioners and commissioners to strengthen the use of LCA as a policy tool.

Acknowledgments The authors wish to thank the coordinators and students of the Industrial Ecology education program at Leiden University and Delft University of Technology for their helpful and incisive comments on a presentation of an early version of this paper. The authors would also like to thank two anonymous reviewers for their valuable comments on a previous draft of the paper.

Open Access This article is distributed under the terms of the Creative Commons Attribution License which permits any use, distribution, and reproduction in any medium, provided the original author(s) and the source are credited.

\section{References}

Ayer NW, Tyedmers PH, Pelletier NL, Sonesson U, Scholz A (2007) Co-product allocation in life cycle assessments of seafood production systems: review of problems and strategies. Int $\mathrm{J}$ Life Cycle Assess 12(7):480-487

Bier JM, Verbeek CJR, Lay MC (2012) An eco-profile of thermoplastic protein derived from blood meal. Part 1: allocation issues. Int $\mathrm{J}$ Life Cycle Assess 17(2):208-219

Bindraban P, Pistorius R (2008) Biofuels and food security. Plant Research International, Wageningen

Brookes G (2001) The EU animal feed sector: protein ingredient use and the implications of the ban on use of meat and bonemeal. BrookesWest, Elham, Canterbury, UK

CBS (2007) Compendium voor de Leefomgeving. Available from: http://www.compendiumvoordeleefomgeving.nl/onderwerpen/ nl0006-Energie-en-milieu.html?i=6. Accessed on 5 June 2011. 
CEC (Commission of the European Communities) (2007) Biofuels Progress Report: Report on the progress made in the use of biofuels and other renewable fuels in the member states of the European Union. Brussels, Belgium

Chum H, Faaij APC, Moreira JR, Berndes G, Dhamija P, Dong H, Gabriella B, Goss Eng A, Lucht W, Mapako M, Masera Cerutte M, McIntyre T, Minowa T, Pingoud K (2011) Bioenergy. In: Edenhoffer O, Pichs-Madruga R, Sokona Y (eds) IPCC Special Report on Renewable Energy Sources and Climate Change. Cambridge University Press, Unitid Kingdom and New York, NY, USA

Corbett RR (2008) Peas as a protein and energy source for ruminants. Available from http://www.wcds.ca/proc/1997/ch18-97.htm. Accessed on 5 June 2011

De Fraiture C, Giordano M, Liao Y (2008) Biofuels and implications for agricultural water use: blue impacts of green energy. Water Pol 10(1):67-81

Directive 2009/28/EC (2009) Directive 2009/28/EC of the European Parliament and of the Council of April 23, 2009 on the promotion of the use of energy from renewable sources and amending and subsequently repealing Directives 2001/77/EC and 2003/30/EC. Brussels, Belgium

Ekvall T, Tillman A (1997) Open-loop recycling: criteria for allocation procedures. Int J Life Cycle Assess 2(3):155-162

CEPA (California Environmental Protection Agency) (2009) Detailed California-Modified GREET Pathway for Conversion of Midwest Soybeans to Biodiesel (Fatty Acid Methyl Esters-FAME)

EPA (United States Environmental Protection Agency) (2010) RFS2: Regulation of Fuel and Fuel Additives: Modifications to Renewable Fuel Standard Program

European Commission-Joint Research Centre-Institute for Environment and Sustainability (2010) International Reference Life Cycle Data System (ILCD) Handbook-general guide for life cycle assessment - detailed guidance. Luxemburg

Finnveden G, Lindfors L (1998) Data quality of life cycle inventory data-rules of thumb. Int J Life Cycle Assess 3(2):65-66

Guinée J (ed) (2002) Handbook on life cycle assessment operational guide to the ISO standards. Kluwer, Dordrecht

Guinée JB, Heijungs R (2007) Calculating the influence of alternative allocation scenarios in fossil fuel chains. Int J Life Cycle Assess 12(3):173-180

Guinée J, Heijungs R, Huppes G (2004) Economic allocation: examples and derived decision tree. Int J Life Cycle Assess 9(1):23-33

Guinée J, Heijungs R, van der Voet E (2009) A greenhouse gas indicator for bioenergy: some theoretical issues with practical implications. Int J Life Cycle Assess 14(4):328-339

Hamelinck C, Koop K, Kroezen H, Koper M, Kampman B, Bergsma G (2008) Technical specification: greenhouse gas calculator for biofuels, Ecofys/CE Utrecht

IPCC et al (2007) In: Solomon S, Qin D, Manning M (eds) Climate change 2007: The physical science basis. Contribution of Working Group I to the fourth assessment report of the
Intergovernmental Panel on Climate Change. Cambridge University Press, New York

ISO 14040 (2006) International Standard ISO 14040: environmental management-life cycle assessment-principles and framework Geneva, Switzerland

Kim S, Dale BE (2002) Allocation procedure in ethanol production system from corn grain I. system expansion. Int J Life Cycle Assess 7(4):237-243

LCFS (Low Carbon Fuel Standard) (2007) Low Carbon Fuel Standard. California

Luo L, van der Voet E, Huppes G, Udo de Haes H (2009) Allocation issues in LCA methodology: a case study of corn stover-based fuel ethanol. Int J Life Cycle Assess 14(6):529-539

Nemecek T, Heil A, Huguenin O, Meier S, Erzinger S, Blaser S, Dux D, Zimmermann A (2000) Life cycle inventories of agricultural production systems Final Report Ecoinvent. Swiss Centre for Life Cycle Inventories, Dubendorf

Reijnders L, Huijbregts M (2008) Palm oil and the emission of carbonbased greenhouse gases. J Clean Prod 16(4):477-482

Searchinger T, Heimlich R, Houghton R, Dong F, Elobeid A, Fabiosa J, Tokgoz S, Hayes D, Yu T (2008) Use of US croplands for biofuels increases greenhouse gases through emissions from landuse change. Science 319(5867): 1238

Seebregts A, Volkers C (2005) Monitoring Nederlandse elektriciteitscentrales 2000-2004 ECN Beleidsstudies. Petten, the Netherlands, ECN

SenterNovem (2008) The greenhouse gas calculation methodology for biomass-based electricity, heat and fuels. Utrecht

Thomassen MA, Dalgaard R, Heijungs R, de Boer I (2008) Attributional and consequential LCA of milk production. Int J Life Cycle Assess 13(4):339-349

RTFO (Renewable Transport Fuel Obligations) (2007) Renewable Transport Fuel Obligations Order 2007

UNEP (United Nations Environmental Program) (2009) Guidelines for social life cycle assessment of products. Paris, France

United States Department of Energy (2010) Growing America's energy future: renewable bioenergy

Van der Voet E, Van Oers L, Davis C, Nelis R, Cok B, Heijungs R, Chappin E, Guinée J (2008) Greenhouse gas calculator for electricity and heat from biomass. CML Institute of Environmental Sciences, Leiden

Van der Voet E, Lifset RJ, Luo L (2010) Life-cycle assessment of biofuels, convergence and divergence. Biofuels 1(3):435-449

Wang M, Lee H, Molburg J (2004) Allocation of energy use in petroleum refineries to petroleum products. Int J Life Cycle Assess 9(1):34-44

Weidema BP, Schmidt JH (2010) Avoiding allocation in life cycle assessment revisited. J Ind Ecol 14(2):192-195

Worldwatch Institute (2007) Biofuels for transportation: global potential and implications for sustainable agriculture and energy in the 21 st century. Washington DC 